\title{
EFFECTIVENESS OF NEONATAL RESUSCITATION SIMULATION (NRS) ON KNOWLEDGE REGARDING NEONATAL RESUSCITATION AMONG NURSING STUDENTS IN SELECTED NURSING COLLEGES
}

\author{
Mrs. Brintha Balakrishnamony* | Dr. Balasubramanian N** \\ *PhD (N) Scholar, Himalayan University, Itanagar, Arunachal Pradesh, India. \\ ** Principal cum Professor, Ambika College of Nursing, Mohali, Punjab, India. \\ DOI: http://doi.org/10.47211/trr.2019.v05i02.003 \\ Received $10^{\text {th }}$ October 2019, Accepted $5^{\text {th }}$ December 2019, Published $20^{\text {th }}$ December 2019
}

\begin{abstract}
Background: Every year millions of neonates require breathing assistance immediately after birth. Approximately $10 \%$ of newborns demand some assistance in breathing and less than $1 \%$ requires extensive resuscitative measures (AHA-2015). Perinatal asphyxia is the major reason to neonatal deaths worldwide. Proficiency of health professionals in neonatal resuscitation is essential in delivery rooms and NICU to safeguard the health of neonates. The present study was conducted to assess the knowledge of nursing students before and after intervention.

Objective: The objective of the study was to identify the knowledge of nursing students on neonatal resuscitation before and after Neonatal Resuscitation Simulation (NRS).

Methods: It is a true experimental research design to assess the nursing student's knowledge regarding neonatal resuscitation. Pre-test and post-test were conducted with 100 nursing students in the experimental group and 100 in the control group selected by simple random method. The investigator constructed the knowledge questionnaire with 43 items in the form of MCQs.

Findings of the study: In the experimental group, the overall mean and $S D$ was $32.4 \pm 4.31$ and the overall mean and $S D$ was $17.94 \pm 4.02$ in the control group. Computed unpaired " $t$ " value was $24.52(p<0.001)$ which was highly significant.

Conclusion: The study findings revealed that the nursing students' knowledge on neonatal resuscitation was inadequate in pre-test. Nevertheless, it was improved after intervention. Hence, the study recommended NRS to the health personnel for improving their knowledge.
\end{abstract}

KEYWORDS: Neonatal resuscitation simulation, neonatal resuscitation, nursing students.

\section{ABOUT AUTHORS:}

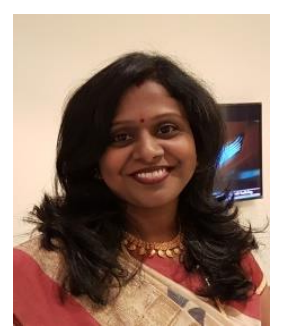

Author Mrs. Brintha Balakrishnamony is Research Scholar in Himalayan University, Arunachal Pradesh, India. She has attended various Seminars and conferences.

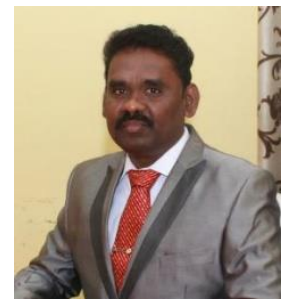

Author Dr. Balasubramanian $\mathrm{N}$ is an active researcher with many publications in his name. He has attended and organised various National and International conferences and has given extensive lectures. At present he is Professor cum Principal in Ambika College of Nursing, Mohali, Punjab, India. 


\section{INTRODUCTION}

Every year nearly $41 \%$ of all under-five child deaths are among newborn infants, babies in their first 28 days of life or the neonatal period (WHO-2011). Neonatal mortality occurs mainly due to perinatal asphyxia, sepsis, prematurity. According to Global Health Observatory (GHO) data, skilled birth attendants could prevent most obstetric complications. Globally almost $80 \%$ of live births occurred with the assistance of skilled health personnel in the period of 2012-2017 (WHO-2019). Beginning of natural breathing after birth is the most essential step for the survival of a newborn baby. Skilful Neonatal Resuscitation (NR) has the capacity to prevent these perinatal mortalities related to birth asphyxia. Organised knowledge and recognising the time to undertake resuscitation procedure in the neonate is essential for reducing the number of complications in newborns. Deficiency in proper resuscitative care leads to high neonatal mortality which is preventable.

\section{PURPOSE OF THE STUDY}

The purpose of the study was to identify the knowledge of nursing students before and after Neonatal Resuscitation Simulation (NRS). This study could help the nursing students gain knowledge to undertake neonatal resuscitation procedures in emergency and could reduce the complications in life-threatening situations.

\section{OBJECTIVES OF THE STUDY}

- To determine the pre-test level of knowledge of nursing students on neonatal resuscitation.

- To develop and implement simulation teaching (NRS) on neonatal resuscitation.

- To evaluate the effectiveness of Neonatal Resuscitation Simulation (NRS) in terms of gain in level of knowledge score.

\section{MATERIALS AND METHODS}

Research Design: The investigator adopted a true experimental design to observe the changes that take place in cause and effect relationship. A true experimental study is characterised by its properties like manipulation, control and randomisation.

Research setting and population: The study was carried out in selected nursing colleges located in Tirunelveli District of Tamil Nadu. The study population was $4^{\text {th }}$ year undergraduate nursing students.

Sampling technique: Sampling technique of this study was simple random technique, which comes under probability sampling wherein the elements are selected at random. A total of 200 nursing students who were studying in $4^{\text {th }}$ year B.Sc. (nursing), were selected.

\section{Description of the Instrument -}

Socio-Demographic Data: It was developed according to the needs of the current study by the investigator i.e. age of the student; gender of the student; number of times neonatal assessment performed in hospital; number of times participated in the team of neonatal resuscitation and source of knowledge on neonatal resuscitation.

Knowledge questionnaire: The investigator developed the items based on the blueprint and selected Multiple Choice Questions (MCQ) format. Totally 43 questions were constructed of which six items related to the introduction of neonatal resuscitation; preliminary assessment contained eight items with three items on care of newborn during resuscitation, three items on airway, seven items on ventilation, six items on chest compressions on neonatal resuscitation; administration of medication consisted of three items and care after NCPR contained five items.

Data collection procedure: After obtaining written permission from the institutions, written informed consent was taken from the student participants. Demographic data was collected first and then the knowledge questionnaire was issued and collected. After that, Neonatal Resuscitation Simulation (NRS) teaching was imparted with the help of infant mannequin. After 2 weeks of intervention, post-test was conducted with the same questionnaire. The data collection time with the questionnaire was approximately $30-35$ minutes. 


\section{ARTICLES}

Statistical Analysis: Descriptive and inferential statistics were used for analysing the data. Data was analysed in Statistical Package for Social Science (SPSS) 16 version.

\section{RESULTS}

Table 1: Frequency and percentage wise distribution of demographic variables of nursing students

\begin{tabular}{|c|c|c|c|c|c|c|}
\hline \multirow{2}{*}{$\begin{array}{l}\text { Sl. } \\
\text { No, }\end{array}$} & \multirow{2}{*}{\multicolumn{2}{|c|}{ Demographic data }} & \multicolumn{2}{|c|}{ Control group $(n=100)$} & \multicolumn{2}{|c|}{ Experimental group $(n=100)$} \\
\hline & & & $\mathbf{f}$ & $\%$ & $\mathbf{f}$ & $\%$ \\
\hline \multirow[t]{3}{*}{1.} & \multirow[t]{3}{*}{ Age (in years) } & 19 years & 0 & 0 & 0 & 0 \\
\hline & & 20 years & 95 & 95 & 88 & 88 \\
\hline & & 21 years and above & 5 & 5 & 12 & 12 \\
\hline \multirow{2}{*}{2.} & \multirow{2}{*}{ Gender } & Male & 0 & 0 & 0 & 0 \\
\hline & & Female & 100 & 100 & 100 & 100 \\
\hline \multirow[t]{4}{*}{3.} & \multirow{4}{*}{$\begin{array}{l}\text { Number of times neonatal } \\
\text { assessment performed : }\end{array}$} & 1-5 times & 5 & 5 & 9 & 9 \\
\hline & & $6-10$ times & 0 & 0 & 2 & 2 \\
\hline & & More than 10 times & 0 & 0 & 0 & 0 \\
\hline & & Did not perform & 95 & 95 & 89 & 89 \\
\hline \multirow[t]{3}{*}{4.} & \multirow[t]{3}{*}{ Number of times participated } & $1-5$ times & 2 & 2 & 9 & 9 \\
\hline & & More than 5 times & 0 & 0 & 2 & 2 \\
\hline & & None & 98 & 98 & 89 & 89 \\
\hline \multirow[t]{4}{*}{5.} & \multirow[t]{4}{*}{ Source of knowledge } & Academic & 95 & 95 & 89 & 89 \\
\hline & & Clinical experience & 5 & 5 & 9 & 9 \\
\hline & & Seminars/workshops & 0 & 0 & 1 & 1 \\
\hline & & Web pages & 0 & 0 & 1 & 1 \\
\hline
\end{tabular}

Table - 1 shows that $95 \%$ of control group and $88 \%$ of experimental group belonged to the age group of 20 years. $5 \%$ in control group and 9\% in experimental group performed neonatal assessment 1-5 times and 95\% in control group and $89 \%$ in experimental group did not perform neonatal assessment. Only $2 \%$ in control group and $9 \%$ in experimental group participated in neonatal resuscitation. Source of knowledge of majority of nursing students in the control group (95\%) and experimental group (89\%) was through their academic performance.

Table - 2: Frequency and percentage of control and experimental group level of knowledge on neonatal resuscitation

$N=(100+100)=200$

\begin{tabular}{|l|c|c|c|c|c|c|c|c|}
\hline \multirow{2}{*}{ Level of knowledge } & \multicolumn{4}{|c|}{ Control group } & \multicolumn{4}{c|}{ Experimental group } \\
\cline { 2 - 10 } & Pre-test Score & Post test score & \multicolumn{2}{c|}{ Pre-test Score } & \multicolumn{2}{c|}{ Post-test score } \\
\cline { 2 - 10 } & $\mathbf{f}$ & $\%$ & $\mathbf{f}$ & $\%$ & $\mathbf{f}$ & $\%$ & $\mathbf{f}$ & $\%$ \\
\hline Poor & 25 & 25 & 19 & 19 & 31 & 31 & 0 & 0 \\
\hline Average & 75 & 75 & 80 & 80 & 69 & 69 & 19 & 19 \\
\hline Good & 0 & 0 & 1 & 1 & 0 & 0 & 81 & 81 \\
\hline Total & 100 & 100 & 100 & 100 & 100 & 100 & 100 & 100 \\
\hline
\end{tabular}

Table 2 presents that in pre-test, 69\% of experimental group and 75\% of control group had average levels of knowledge on neonatal resuscitation. $31 \%$ of experimental group and $25 \%$ of control group had poor knowledge before the implementation of NRS. In post-test, $81 \%$ of the experimental group had good knowledge level and $19 \%$ had average knowledge level. In control group, majority $80 \%$ had average knowledge level, $19 \%$ had poor knowledge level and $1 \%$ had good knowledge on neonatal resuscitation.

\section{Percentage of samples based on Pre-test and Post-test Levels of Knowledge}




\section{ARTICLES}

\section{$\square$ Poor $\square$ Average $\square$ Good}

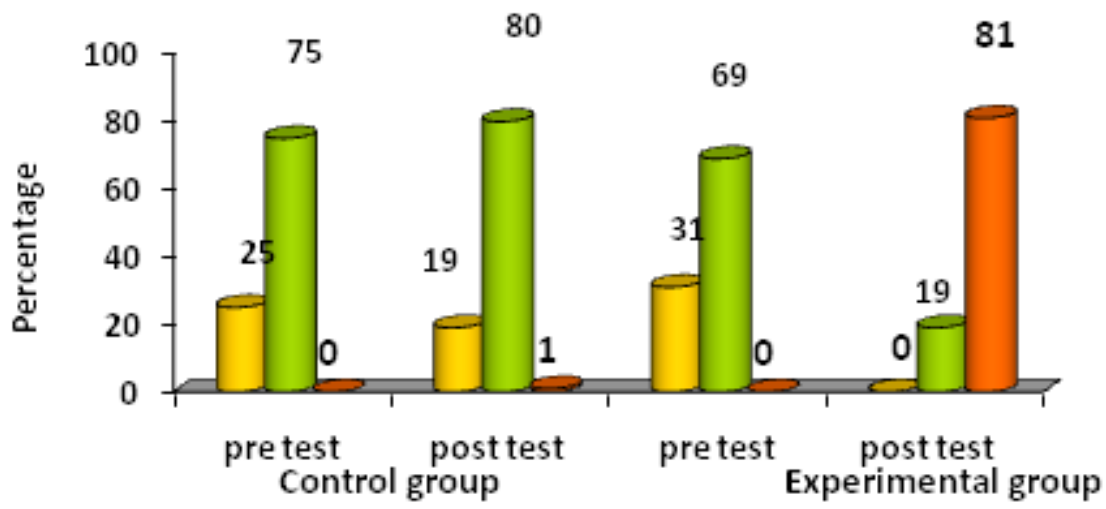

\section{Level of Knowledge}

Figure - 1: Level of knowledge scores before and after implementation of NRS

Figure - 1 cylinder diagram shows that in pre-test, highest percentage of them in experimental group (69\%) and in the control group (75\%) had average knowledge; whereas, $31 \%$ in experimental group and $25 \%$ in control group had poor knowledge. In post-test, $81 \%$ of experimental group had good knowledge and 19\% had poor knowledge; whereas, $80 \%$ had average knowledge and $19 \%$ had poor knowledge in the control group. From the findings, it can be interpreted that NRS improved the level of knowledge among nursing students significantly higher in experimental group than in the control group.

\section{Comparison of Pre-test and Post-test knowledge scores -}

Comparison in pre-test of Mean, SD and Mean \% of knowledge: Out of maximum achievable score of 43 in the experimental group, the overall mean and SD was $16.73 \pm 4.05$, which is $39 \%$ of total score. The overall mean and SD was $17.3 \pm 4.01$ in the control group, which was $40 \%$ of total score. In both the groups, the pre-test knowledge scores revealed poor knowledge before implementation of NRS on neonatal resuscitation. The data is also presented in line graph format as shown in Figure - 2

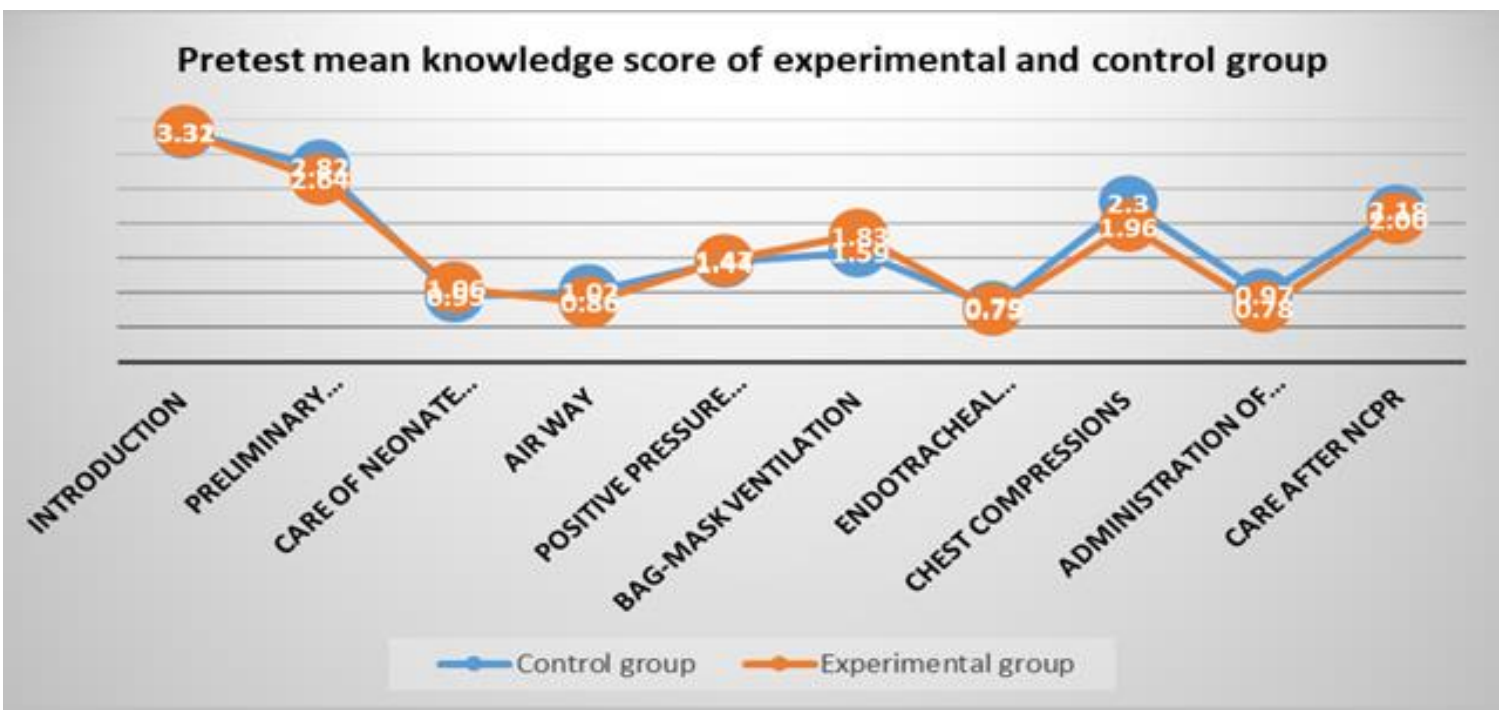

Figure - 2: Line graph showing the Pre-test mean knowledge score of Experimental and Control group 


\section{ARTICLES}

Comparison in Post-test of Mean, SD and Mean \% of knowledge: Out of maximum attainable score of 43 , the overall mean and SD was32.4 \pm 4.31 , which is $75 \%$ of total score in the experimental group and the overall mean and SD was $17.94 \pm 4.02$ in the control group, which is $42 \%$ of total score. The data is presented in line graph below -

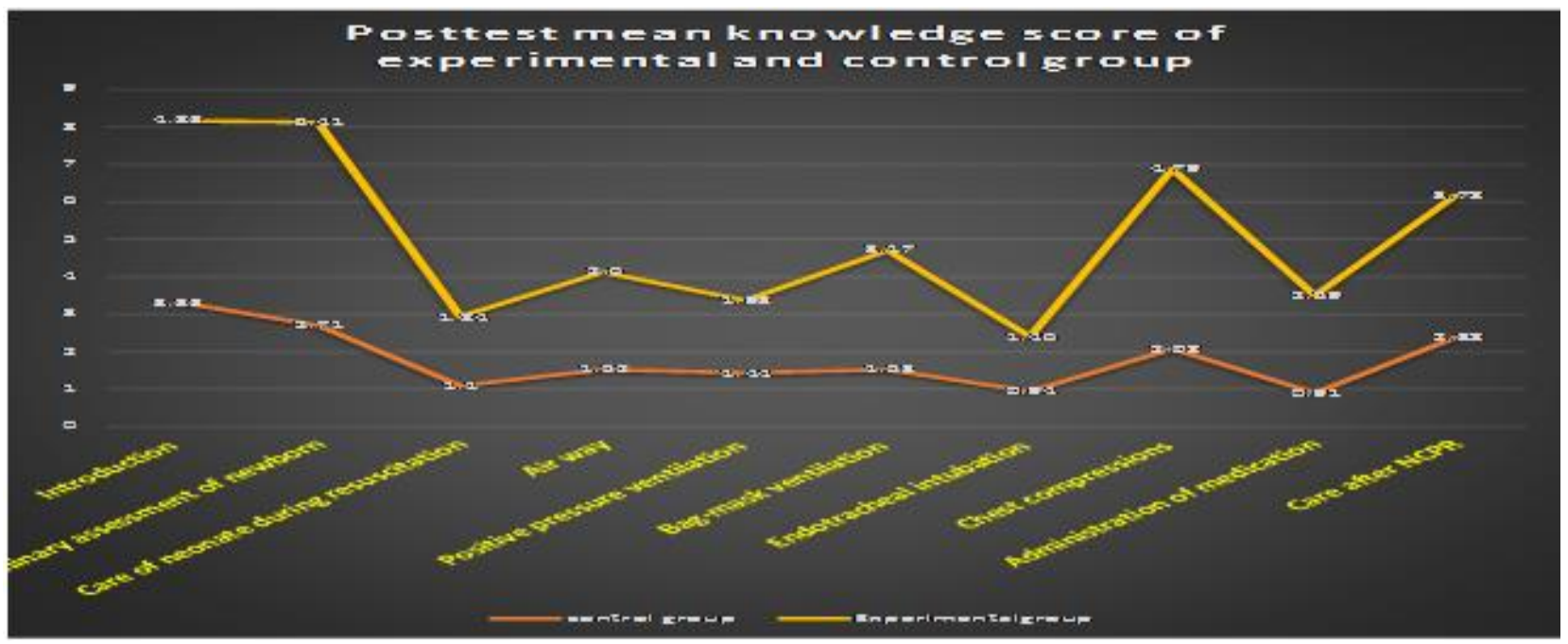

Figure - 3: Line graph showing the Post-test mean knowledge score of experimental and control groups.

Table - 3: Paired ' $t$ ' test to assess the efficacy of NRS on knowledge among nursing students

$N=(100+100)=200$

\begin{tabular}{|c|c|c|c|c|c|c|c|}
\hline \multirow{2}{*}{ Knowledge } & \multicolumn{2}{|c|}{ Experimental pre- test } & \multicolumn{2}{|c|}{ Experimental post- test } & \multirow{2}{*}{$\begin{array}{c}\text { Mean } \\
\text { difference }\end{array}$} & \multirow{2}{*}{$\begin{array}{l}\text { 't'- } \\
\text { value }\end{array}$} & \multirow{2}{*}{ P-value } \\
\hline & Mean & SD & Mean & SD & & & \\
\hline Introduction & 3.32 & 1.14 & 4.83 & 1.11 & 1.51 & 9.97 & $\mathrm{P}<0.001 * * *$ \\
\hline $\begin{array}{l}\text { Preliminary assessment } \\
\text { of newborn }\end{array}$ & 2.64 & 1.57 & 5.41 & 1.66 & 2.77 & 13.05 & $\mathrm{P}<0.001^{* * *}$ \\
\hline $\begin{array}{l}\text { Care of neonate during } \\
\text { resuscitation }\end{array}$ & 1.06 & 0.74 & 1.84 & 0.77 & 0.78 & 7.23 & $\mathrm{P}<0.001 * * *$ \\
\hline Air way & 0.86 & 0.83 & 2.6 & 0.57 & 1.74 & 17.2 & $\mathrm{P}<0.001 * * *$ \\
\hline $\begin{array}{l}\text { Positive pressure } \\
\text { ventilation }\end{array}$ & 1.47 & 0.94 & 1.93 & 0.79 & 0.46 & 3.40 & $\mathrm{P}<0.001^{* * *}$ \\
\hline Bag-mask ventilation & 1.83 & 0.93 & 3.17 & 0.65 & 1.34 & 11.76 & $\mathrm{P}<0.001 * * *$ \\
\hline Endotracheal intubation & 0.75 & 0.51 & 1.46 & 0.64 & 0.71 & 8.92 & $\mathrm{P}<0.001 * * *$ \\
\hline Chest compressions & 1.96 & 1.18 & 4.79 & 0.96 & 2.83 & 18.56 & $\mathrm{P}<0.001 * * *$ \\
\hline $\begin{array}{l}\text { Administration of } \\
\text { medication }\end{array}$ & 0.78 & 0.62 & 2.59 & 0.63 & 1.81 & 20.74 & $\mathrm{P}<0.001^{* * *}$ \\
\hline Care after NCPR & 2.06 & 1.06 & 3.78 & 0.97 & 1.72 & 12.61 & $\mathrm{P}<0.001 * * *$ \\
\hline OVEALL & 16.73 & 4.05 & 32.4 & 4.31 & 15.67 & 26.84 & $\mathrm{P}<0.001 * * *$ \\
\hline
\end{tabular}

Table-3 describes the overall knowledge Mean, SD was 16.73 4.05 in the pre-test experimental group and the Mean, SD was 32.4 4.31 in post-test experimental group. The mean difference between pre- and post-test of experimental group was 15.67 and obtained paired " $t$ " value for experimental group was 26.84 ( $p<0.001$ ) which was highly significant. 
Table 4: Unpaired ' $t$ ' test to assess the Post-test efficacy of neonatal resuscitation simulation (NRS) on knowledge between control and experimental groups among nursing students

$$
N=(100+100)=200
$$

\begin{tabular}{|c|c|c|c|c|c|c|c|}
\hline \multirow{2}{*}{ Knowledge } & \multicolumn{2}{|c|}{ Control Post-test } & \multicolumn{2}{|c|}{ Experimental post- test } & \multirow{2}{*}{$\begin{array}{c}\text { Mean } \\
\text { difference }\end{array}$} & \multirow{2}{*}{ 't'-value } & \multirow{2}{*}{ P-value } \\
\hline & Mean & SD & Mean & SD & & & \\
\hline Introduction & 3.33 & 1.14 & 4.83 & 1.11 & 1.5 & 9.39 & $\mathrm{P}<0.001 * * *$ \\
\hline $\begin{array}{l}\text { Preliminary assessment } \\
\text { of newborn }\end{array}$ & 2.71 & 1.58 & 5.41 & 1.66 & 2.7 & 11.75 & $\mathrm{P}<0.001 * * *$ \\
\hline $\begin{array}{l}\text { Care of neonate during } \\
\text { resuscitation }\end{array}$ & 1.1 & 0.75 & 1.84 & 0.77 & 0.74 & 6.88 & $\mathrm{P}<0.001 * * *$ \\
\hline Air way & 1.52 & 0.70 & 2.6 & 0.57 & 1.08 & 11.94 & $\mathrm{P}<0.001 * * *$ \\
\hline $\begin{array}{l}\text { Positive pressure } \\
\text { ventilation }\end{array}$ & 1.44 & 1.38 & 1.93 & 0.79 & 0.49 & 3.06 & $\mathrm{P}=0.002^{* *}$ \\
\hline Bag-mask ventilation & 1.53 & 1.09 & 3.17 & 0.65 & 1.64 & 12.85 & $\mathrm{P}<0.001 * * *$ \\
\hline Endotracheal intubation & 0.94 & 0.73 & 1.46 & 0.64 & 0.52 & 5.32 & $\mathrm{P}<0.001^{* * *}$ \\
\hline Chest compressions & 2.08 & 1.63 & 4.79 & 0.96 & 2.71 & 14.25 & $\mathrm{P}<0.001 * * *$ \\
\hline $\begin{array}{l}\text { Administration of } \\
\text { medication }\end{array}$ & 0.91 & 0.86 & 2.59 & 0.63 & 1.68 & 15.63 & $\mathrm{P}<0.001 * * *$ \\
\hline Care after NCPR & 2.38 & 1.36 & 3.78 & 0.97 & 1.4 & 8.37 & $\mathrm{P}<0.001 * * *$ \\
\hline OVEALL & 17.94 & 4.02 & 32.4 & 4.31 & 14.46 & 24.52 & $\mathrm{P}<0.001 * * *$ \\
\hline
\end{tabular}

Table-4 depicts that, the overall mean and SD was $32.4 \pm 4.31$ in the experimental group and the overall mean and SD was $17.94 \pm 4.02$ in the control group. The overall mean difference between pre-test and post-test was 14.46 and the obtained unpaired " $\mathrm{t}$ " value was $24.52(\mathrm{p}<0.001)$ which was highly significant. It clearly indicates that the mean post-test knowledge score of nursing students on Neonatal Resuscitation in the experimental group will be significantly higher than that of post-test control group as measured by structured knowledge questionnaire on Neonatal Resuscitation.

\section{DISCUSSION}

In the experimental group, the mean post-test knowledge score was $32.4 \pm 4.31$ which was significantly higher than in the pre-test knowledge score of $16.73 \pm 4.05$ with the computed paired " $t$ " value of $26.84(p<0.001)$ being highly significant compared to control group. The computed post-test unpaired " $t$ " value ( $t=24.52, p<0.001$ ) was highly significant compared to pre-test unpaired " $\mathrm{t}$ " value of $(\mathrm{t}=1.12, \mathrm{p}>0.001)$. The findings of the present study exhibit that the post-test knowledge was significantly improved than in the pre-test. These results explain that the knowledge score of experimental group was significantly higher than that in the control group. Hence, $\mathrm{H}_{01}$ is rejected and $\mathrm{H}_{1}$ is accepted. Thus, it is concluded that STM is effective in terms of gain in knowledge score.

Similar findings were also reported by Karakoc A, Demirgoz M, Bingol FB and Aslan B (2019) as in the present study since the differences in the mean total scores and all sub-dimension scores were found to be significant in favour of the experimental group, the score being $95.17 \pm 2.13$ there, as against in the control group where it was $61.27 \pm 8.12$ after the intervention of simulation based training. These findings were consistent with the present study findings.

Subbiah N, Sarin J, Jeeva S and Geetanjali (2012) conducted an interventional study on neonatal resuscitation to assess the pre- and post-test improvement of knowledge. The study findings revealed that the mean pre-test knowledge (19.11 \pm 0.21$)$ was less than the mean post-test knowledge $(30.71 \pm 0.21)$ and the difference was statistically significant $(t=23.5, p<0.05)$. These results are consistent with the findings of the present study proving effectiveness of intervention. 


\section{CONCLUSION}

Before intervention with Neonatal Resuscitation Simulation (NRS), the nursing students had poor knowledge on neonatal resuscitation. After implementing NRS, the knowledge level was good in experimental group. Hence, NRS is essential to improve the knowledge of nursing students for providing quality nursing care to the neonates thereby reducing mortality and morbidity during their complicated life-threatening situations.

\section{REFERENCE}

1. Barber CA, Wyckoff $\mathrm{MH}$, Use and efficacy of endotracheal versus intravenous epinephrine during neonatal cardiopulmonary resuscitation in the delivery room. Pediatrics. 2006; 118:1028-103.

https://www.ncbi.nlm.nih.gov/pubmed/16950994

2. Cisse L, Joseph $\mathrm{G}$ et.al., a cross-sectional study, which took place from March 28 to July 28,2016 , Knowledge and Practices of Neonatal Resuscitation by Health Providers in Côte d'Ivoire Scientific Research, Vol.7 No.3, September 2017, https://www.scirp.org/journal/paperinformation. aspx?paperid=78217

3. Gauro $P$, Saha A, Adhikari B. Knowledge and skill of newborn resuscitation among nurses working in maternity ward. Int J Health Sci Res. 2018; 8(2):149-154. http://www.ijhsr.org/IJHSR_Vol.8_Issue.2_Feb2018/19.pdf

4. Ingham B, A nurses' guide to the critical reading of research, Australian journal of advanced nursing, Volume 26, Number 1,105,

https://www.researchgate.net/publication/273380775_A_nurses'guide_to_the_critical_reading_of_research

5. Karakoc A, Demirgoz M, Bingol FB and Begum Aslan, The effects of simulation-based education on initial neonatal evaluation and care skills, Pakistani Journal of medical sciences, 2019 Jul-Aug; 35(4): 911-917, doi: 10.12669/pjms.35.4.350, https://www.ncbi.nlm.nih.gov/pmc/articles/PMC6659065/

6. Nasortaha FA, study on assessment of knowledge, Attitude and Practices of nurse midwives towards immediate care of the newborn in Khartoum state teaching hospitals, Journal of American Science, 2013;9(9). http://www.jofamericanscience.org/journals/amsci/am0909/034_20235am0909_263_270.pdf

7. Perlman JM, Risser R, Cardiopulmonary resuscitation in the delivery room: associated clinical events. Arch PediatrAdolesc Med. 1995; 149:20-25. https://www.ncbi.nlm.nih.gov/pubmed/7827654

8. Saeidi $R$ and Gholami M, Comparison of Effect of Simulation-based Neonatal Resuscitation Education and Traditional Education on Knowledge of Nursing Students, Iranian Journal of Neonatology 2017; 8(2), DOI: 10.22038/ijn.2017.23740.1296, http://ijn.mums.ac.ir/article_9026_71f27955fb1368d6377553ba4c9157f4.pdf

9. Subbiah N, Sarin J, Jeeva S and Geetanjali, Effectiveness of educational intervention on neonatal resuscitation among nursing personnel, Health and Population - Perspectives and Issues 35(1), 36-45, 2012, http://medind.nic.in/hab/t12/i1/habt12i1p36.pdf

10. Weiner GM., Zaichkin J., Text book of Neonatal resuscitation, American academy of pediatrics, 7th edition, page: 44,68,165,183,213. https://shop.aap.org/textbook-of-neonatal-resuscitation-7th-edition-paperback/

11. WHO, Newborn death and illness, Millennium Development Goal Four (MDG-4), the partnership for maternal, newborn \& child health, 2011. https://www.who.int/pmnch/media/press_materials/fs/fs_newborndealth_illness/en/

12. World Health Organization, Global Health Observatory data, Data and analysis for health and health related SDGs, https://www.who.int/gho/en/

13. Wyckoff MH, Aziz K, et.al., 2015 American Heart Association guidelines update for cardio pulmonary resuscitation and emergency cardio vascular care, Circulation, Nov: 3, 2015, Volume 132, Issue: 18, Sup.2, https://ahajournals.org/doi/full/10.1161/cir.0000000000000267 